\title{
Misverstanden over trauma: een illustratie aan de hand van ervaringen met geweld uit naam van de familie-eer
}

\author{
Elisa van Ee \& Janine Janssen
}

\begin{abstract}
Een jonge vrouw uit een gezin dat van oorsprong uit het Midden-Oosten komt, is een relatie aangegaan met een Zuid-Amerikaan. Haar vader is hier zeer ontstemd over. Hij ziet een andere toekomst voor zijn dochter voor zich. Thuis wordt regelmatig geweld gebruikt en ook nu zijn de dreigementen niet van de lucht. Inmiddels is door een deskundige vastgesteld dat de vader lijdt aan een posttraumatische stressstoornis. Het ontstaan van deze stoornis wordt toegeschreven aan de ervaringen die hij in een oorlogsgebied heeft opgedaan. De vraag is nu of het geweld in huis verklaard kan worden door naleving van culturele codes over correct gedrag van familieleden. Of speelt het oorlogsleed een doorslaggevende rol bij het gewelddadige gedrag?
\end{abstract}

\section{Inleiding}

Het hiervoor gegeven voorbeeld is afkomstig uit een handboek over de achtergronden en aanpak van geweld uit naam van de familie-eer. ${ }^{1}$ Kwesties rond familie-eer gaan vaak over het aangaan en verbreken van relaties zonder instemming van de familie en over seksualiteit buiten het huwelijk. In dit verband kan onder meer gedacht worden aan buitenechtelijke relaties en zwangerschappen. Doorgaans worden verklaringen voor de gehechtheid aan die opvattingen over de familie-eer gezocht in culturele achtergronden. Maar met name bij de politie leeft al geruime tijd het inzicht dat bij de casuïstiek die daar in beeld komt ook andere factoren een rol spelen. ${ }^{2}$ Zo krijgt de politie veel zaken in beeld waarbij mensen betrokken zijn die uit een oorlogsgebied komen. ${ }^{3}$ De gemiddelde krantenlezer weet inmiddels ook dat het niet goed toeven is in brandhaarden in onder meer

* Dr. mr. Elisa van Ee is klinisch psycholoog en onderzoeker bij het Psychotraumacentrum ZuidNederland, Reinier van Arkel en Behavioural Science Institute, Radboud Universiteit. Tevens is zij als extern deskundige op het gebied van trauma verbonden aan het Landelijk Expertise Centrum Eer Gerelateerd Geweld van de Nationale Politie. Prof. dr. Janine Janssen is hoofd onderzoek van het Landelijk Expertise Centrum Eer Gerelateerd Geweld van de Nationale Politie, lector Veiligheid in Afhankelijkheidsrelaties aan Avans Hogeschool, bijzonder hoogleraar Rechtsantropologie aan de Open Universiteit en voorzitter van de redactie van PROCES.

1 J. Janssen, Focus op eer. Een verkenning van eerzaken voor politieambtenaren en andere professionals, Den Haag: Boom criminologie 2017.

2 J. Janssen, 'Discussie: over culturele en andere achtergronden van eergerelateerd geweld', Tijdschrift voor Criminologie, 2007 4, p. 400-406.

3 J. Janssen \& R. Sanberg, 'Eer op de vlucht. Over eergerelateerd geweld in Nederlandse Asielzoekerscentra', Tijdschrift voor Veiligheid, 2017 2, p. 54-71. 
Oost-Afrika en het Midden-Oosten. Ook is bekend dat de reis naar Europa - en dus ook naar Nederland - niet zonder gevaren is. Het is dus geen vreemde gedachte dat die (gewelddadige) ervaringen mede van invloed kunnen zijn op hoe mensen zich voelen en gedragen.

Bij complexe zaken als eergerelateerd geweld kan de politie een beroep doen op externe deskundigen. Die deskundigen kunnen alleen met tussenkomst van het Landelijk Expertise Centrum Eer Gerelateerd Geweld (LEC EGG) van de Nationale Politie worden ingeschakeld. Deskundigen kunnen in de fase van het opsporingsonderzoek een belangrijke rol spelen bij het identificeren van zoekrichtingen en strategieën voor het maken van een plan van aanpak. Het gaat om ervaren wetenschappers op het gebied van taal, cultuur en religie van die etnische groepen die in de casuïstiek in beeld komen. Ook wordt er een beroep gedaan op deskundigheid op het gebied van trauma. ${ }^{4}$ In de praktijk is er steeds meer aandacht voor trauma. Tegelijkertijd zien wij dat er veel misverstanden zijn die tot ongenuanceerd gebruik van terminologie op het terrein van trauma kunnen leiden. In deze bijdrage willen wij een aantal van die misverstanden onder de aandacht brengen.

De posttraumatische stressstoornis (PTSS) wordt dikwijls gezien als symbool voor alles wat een mens op het gebied van trauma kan meemaken. Maar vaak speelt er veel meer en aan het niet onderbouwde gebruik van het etiket trauma kleven grote risico's. In de eerste paragraaf gaan wij dieper in op dat onderwerp. In de tweede paragraaf vragen wij ons vervolgens af in hoeverre PTSS een verklaring biedt voor issues in het leven van de betroffene. In paragraaf 3 kijken wij verder naar de aanpak van trauma. De laatste jaren krijgt met name Eye Movement Desensitization and Reprocessing aandacht. Soms lijkt het alsof dat het enige stuk gereedschap is om trauma te behandelen. Maar traumabehandeling vraagt om maatwerk en het kiezen van het juiste gereedschap. In deze bijdrage behandelen wij een aantal misvattingen over trauma aan de hand van voorbeelden die te maken hebben met eergerelateerd geweld.

\section{$1 \quad$ PTSS als moeder aller trauma's}

Het is misschien geen prettige constatering, maar schokkende gebeurtenissen horen bij het leven. Naar verluidt maakt 80 tot $90 \%$ van de mensen in hun leven een schokkende gebeurtenis mee die zij als traumatisch kunnen ervaren. ${ }^{5}$ Dergelijke gebeurtenissen kunnen het welzijn sterk beïnvloeden; mensen voelen zich hierna bijvoorbeeld lusteloos en somber, hebben nachtmerries of raken snel in paniek. Deze klachten kun je zien als een normale reactie op een ingrijpende ervaring en gaan meestal binnen enkele maanden over. Pas wanneer ernstige klachten blijven bestaan, spreken we van een stoornis in reactie op schokkende gebeurtenissen zoals een aanpassingsstoornis, rouwstoornis, depressieve stoornis, angststoornis of PTSS. PTSS is de enige stoornis waarbij een relatie moet bestaan

4 Zie voor meer achtergrondinformatie over de inzet van deskundigen op het gebied van eergerelateerd geweld ten behoeve van de politie: Janssen 2017.

5 E. Vermetten, R.J. Kleber \& O. van der Hart, Handboek Posttraumatische stressstoornissen, Utrecht: de Tijdstroom 2012. 
tussen de traumatische ervaring en de bijbehorende symptomen. Volgens het Diagnostic and Statistical Manual for Mental Disorders, vijfde editie (DSM-5), ${ }^{6}$ het bekende en veelgebruikte diagnostisch handboek voor psychologen en psychiaters, moet voor het diagnosticeren van een PTSS sprake zijn geweest van 'blootstelling aan een feitelijke of dreigende dood, ernstige verwonding of seksueel geweld', het zogenoemde A-criterium. Dit betekent dat pestervaringen of verwaarlozing, hoe ingrijpend ook voor de persoon, niet voldoen aan het A-criterium en dus niet kunnen leiden tot een PTSS-diagnose. Naast het meemaken van een traumatische ervaring moet een persoon volgens het DSM verschillende symptomen rapporteren uit de vier verschillende clusters van symptomen, namelijk (1) intrusieve (dat betekent letterlijk 'opdringende') symptomen, (2) persisterende vermijding, (3) negatieve verandering in cognities en stemming, en (4) veranderingen in arousal (fysiologische opwinding) en reactiviteit. Onder intrusieve symptomen vallen bijvoorbeeld onvrijwillige, zich als het ware opdringende herinneringen, nachtmerries en flashbacks waarbij het voelt alsof de gebeurtenis opnieuw plaatsvindt. Persisterende vermijding uit zich in het vermijden van herinneringen, pijnlijke gedachten en gevoelens of het vermijden van plaatsen, personen en voorwerpen. Negatieve veranderingen in cognities en stemming blijken bijvoorbeeld uit het onvermogen om zich een belangrijk aspect van de traumatische gebeurtenis te herinneren, negatieve overtuigingen of verwachtingen over zichzelf, anderen of de wereld, verminderde belangstelling voor of verminderde deelname aan belangrijke activiteiten, of gevoelens van onthechting of vervreemding van anderen. En, ten slotte, veranderingen in arousal en reactiviteit uiten zich bijvoorbeeld in prikkelbaar gedrag en woede-uitbarstingen, roekeloos of zelfdestructief gedrag, waakzaamheid, schrikachtigheid en concentratieproblemen. ${ }^{7} \mathrm{Al}$ deze symptomen hangen samen met de gebeurtenis en zijn begonnen of verergerd nadat de traumatische gebeurtenis heeft plaatsgevonden. Daarbij veroorzaakt de stoornis wat in jargon zo mooi 'lijdensdruk' heet of beperkingen in het functioneren op sociaal, beroepsmatig of ander gebied. Bij de eerproblematiek komen we ook mensen tegen die PTSS hebben. De volgende casus dient ter illustratie.

Bij de vader van de jonge vrouw uit het Midden-Oosten heeft de deskundige PTSS vastgesteld. Vader rapporteert namelijk dat hij last heeft van herbelevingen, nachtmerries, enerzijds vermijden van spreken over het verleden, anderzijds excessief opzoeken van vaak schokkende nieuwsbeelden uit het land van herkomst, vervreemding van zijn omgeving, passiviteit (geen activiteiten ondernemen), verhoogde prikkelbaarheid en woede-uitbarstingen. Er is een interactie tussen de symptomen van vader en de huidige gezinsproblematiek. De klachten jagen de gezinsproblematiek aan en de gezinsproblematiek jaagt de klachten aan. De herbelevingen van traumatische ervaringen, waaronder het zien van lijken van verkrachte vrouwen, maken dat hij overmatig bezorgd is over de eer van zijn dochter

6 American Psychiatric Association, Diagnostic and Statistical Manual for Mental Disorders (5e ed.), Washington, DC: APA 2013.

7 American Psychiatric Association 2013 
en zijn familie. Vanwege de combinatie van problematiek wordt vader voor behandeling naar het Psychotraumacentrum Zuid-Nederland verwezen, waar hoogspecialistische traumazorg kan worden geboden. Op basis van de diagnose en gezinsproblematiek wordt een traumagerichte behandeling in combinatie met een systeembehandeling geïndiceerd.

Het is goed dat we ons realiseren dat ook bij de eergerelateerde problematiek PTSS kan optreden. Maar over het algemeen is bij het gebruik van het etiket PTSS wel een belangrijke nuance op zijn plaats: hoewel veel mensen een traumatische ervaring meemaken in hun leven, ontwikkelt ongeveer $4-7 \%$ van deze mensen een PTSS. ${ }^{8}$ PTSS is dus een van de mogelijke reacties op een schokkende gebeurtenis, maar verreweg de meeste mensen reageren veerkrachtig op een dergelijke ervaring. Uit recente discussies in diverse media ${ }^{9}$ blijkt echter hoeveel gewicht er in het maatschappelijk discours aan diagnoses wordt gegeven. Mensen die zich melden voor traumazorg vragen soms zelfs om de diagnose PTSS of zijn opgelucht wanneer hun diagnose besproken wordt ('eindelijk weet ik wat er met mij aan de hand is'). Tegelijkertijd is een diagnose niet meer dan een combinatie van gedragingen die leiden tot een label dat richting moet geven aan de behandeling. Het belang van een diagnose zit in de gerichte behandeling die daarop volgt. Een onjuiste diagnose kan leiden tot een niet effectieve behandeling, langer lijden of zelfs een verergering van klachten, met het risico van chroniciteit. Om die reden mag een diagnose alleen gesteld worden door een psychotherapeut, gezondheidszorgpsycholoog, klinisch psycholoog of psychiater. ${ }^{10}$ Helaas is het ook zo binnen de geestelijke gezondheidszorg (ggz) dat trauma en PTSS gemeengoed zijn geworden. Op tal van ggz-afdelingen vindt traumabehandeling door professionals plaats. Onderzoek en de dagelijkse klinische praktijk leren echter dat de meerderheid van deze professionals onvoldoende geschoold is in imaginaire exposuretherapie of andere traumagerichte behandelingen. ${ }^{11}$ Helaas is de consequentie dat er regelmatig inadequate diagnostiek en behandeling van PTSS plaatsvindt.

8 A. Burri \& A. Maercker. 'Differences in prevalence rates of PTSD in various European countries explained by war exposure, other trauma and cultural value orientation', BMC Research Notes 2014, p. 407.; R.C. Kessler e.a., 'Prevalence, severity, and comorbidity of 12-months DSM-IV disorders in the National Comorbidity Survey replication', Archives of General Psychiatry 2005, p. 617-627.

9 Naar aanleiding van de eerste tv-uitzending van Tygo in de psychiatrie van de EO ontstond er een levendige discussie over diagnoses in de ggz in onder andere de Volkskrant ('Tygo in de psychiatrie is een krachtig statement tegen de toenemende labeldrift in de psychiatrie'), GGZnieuws.nl ('Wat als je de verkeerde labels krijgt'), Het Parool ('Voorlopige diagnose: Tygo Gernandt: vergeet de psychiater') en onder hulpverleners op Linkedin.

10 Model Kwaliteitsinstituut GGZ, versie 1.1.

11 A. Minnen, L. Hendriks \& M. Olff, 'When do trauma experts choose exposure therapy for PTSD patients? A controlled study of therapist and patient factors', Behaviour Research and Therapy 2010, p. 312-320. 


\section{PTSS als verklaring voor alles}

Hoewel de diagnose PTSS een kader geeft om bepaalde gedragingen te verklaren is het bijna nooit een afdoende verklaring voor de problematiek. Waarom de ene persoon met PTSS uit angst onder zijn bed kruipt en de ander uit angst met zijn vuisten erop slaat, kan alleen begrepen worden door vanuit verschillende perspectieven naar de persoon en zijn gedrag in de sociale context te kijken. De ecologische theorie van Bronfenbrenner ${ }^{12}$ is een van de meest geaccepteerde modellen om de invloed van de sociale omgeving op de ontwikkeling van de mens te begrijpen. Gedrag van de persoon wordt in deze theorie geleid door zijn individuele interpretatie van de realiteit. Hoewel biologische factoren een rol spelen bij PTSS, worden de waarneming en het gedrag van een persoon medebepaald door de activiteiten, rollen en interpersoonlijke relaties op verschillende niveaus. Denk aan het gezin, de familie, de buurt en de sociale, culturele, politieke en historische systemen waar de mens onderdeel van is. Factoren interacteren op verschillende niveaus, waardoor gedrag alleen begrepen kan worden door de verschillende niveaus in een gedragsanalyse van de persoon mee te nemen. Juist in de situatie van migranten en vluchtelingen bij wie de levensgeschiedenis getekend kan zijn door sociale, culturele, politieke en historische systemen uit een ander land kan een dergelijke analyse van belang zijn om als 'witte Hollander' de problematiek te begrijpen. Uit een dergelijke analyse blijkt vaak dat het verleden geen verleden is: het gaat letterlijk en figuurlijk om onvoltooid verleden tijd. Factoren als PTSSklachten die het verleden doen herleven, kunnen hierin een rol spelen, maar ook de zogenoemde condición migrante, een combinatie van postmigratie issues verbonden aan het leven van migranten, zoals het verlies van familierelaties, sociale steun en identiteit. ${ }^{13}$ Opnieuw is hier sprake van een interactie: de mate van aanpassing aan een cultuur (acculturatie) draagt bij aan het voortduren van deze conditie. De mogelijkheden om elementen van een nieuwe cultuur over te nemen, zoals de mate waarin culturele aansluiting wordt ervaren en het verwerven van instrumentele vaardigheden om met de andere cultuur om te gaan, worden echter significant beïnvloed door PTSS of andere mentale gezondheidsproblematiek. ${ }^{14}$ Een ander voorbeeld van invloed vanuit de sociale omgeving is stigmatisering, hetgeen de chroniciteit van klachten kan versterken. Hierbij moet niet alleen gedacht worden aan stigmatisering van psychische problematiek, maar ook aan

12 U. Bronfenbrenner, Making human beings human: Bioecological perspectives on human development, Thousand Oaks: Sage Publications 2005.

13 T. Graafsma \& J. Tieken, 'Leven in een "condición migrante”, in: P.A.Q.M. Lamers (red.), Hulpverlening aan migranten: De confrontatie van culturen in de geestelijke gezondheidszorg, Alphen aan den Rijn/Brussel: Samson Stafleu 1987, p. 26-34.

14 J.W. Knipscheer \& R.J. Kleber, 'Acculturation and mental health among Ghanaians in the Netherlands', International Journal of Social Psychiatry 2007, p. 369-383. J.W. Knipscheer \& R.J. Kleber, 'The relative contribution of posttraumatic and acculturative stress to subjective mental health among Bosnian refugees', Journal of Clinical Psychology 2006, p. 339-353. 
stigmatisering van traumatische ervaringen en culturele overtuigingen. ${ }^{15} \mathrm{We}$ illustreren dit punt weer aan de hand van de hiervoor geïntroduceerde casus.

Vanwege de gezinsproblematiek worden in een serie partner- en gezinsgesprekken de gezinswaarden en gezinsverhoudingen bespreekbaar gemaakt. Doordat de behandelaar zich respectvol en 'meervoudig partijdig'16 opstelt, raakt het gezin in gesprek over dat wat zij gezamenlijk verloren hebben door de vlucht vanuit het Midden-Oosten en dat wat zij gezamenlijk hier in Nederland willen behouden. Het lukt vader iets te zeggen over hoe hij zich getekend voelt door trauma en verlies. Des te schrijnender is het voor hem dat hij door de migratie zijn positie als hoofd van het gezin heeft verloren. Door dit verlies hebben het behoud van familiewaarden en het behoud van eer meer gewicht dan eerder voor hem gekregen. Tegelijkertijd voelt hij dat in Nederland de toekomst van zijn kinderen ligt. Doordat dochter het klemzitten tussen twee culturen herkent, lukt het haar om haar vader erkenning te geven als vader. Hierdoor ontstaat er ruimte om afspraken te maken over wanneer en hoe dochter haar vriend mag zien. Vader voelt zich erkend in zijn positie en de woede-uitbarstingen nemen af, maar verdwijnen niet.

De sociaal-cognitieve functies van ons brein zijn zo ingesteld dat de mens de vaak zo dynamische interacties in het dagelijks leven volgens vuistregels kan inschatten. Dat geeft de mens het vermogen om in korte tijd een oordeel te vormen en te handelen. ${ }^{17}$ Het in korte tijd kunnen oordelen en handelen is een noodzakelijke vaardigheid, die echter gemakkelijk kan leiden tot verkeerde interpretaties, verklaringen en gedragingen. Juist in het werken met gezinnen waarin trauma en de dreiging van eergerelateerd geweld spelen, is het van belang oog te hebben voor de verschillende factoren die een rol spelen, en de interacties daartussen, als verklaring voor de ontstane problematiek in het verleden, heden en de toekomst.

\section{EMDR als enige remedie tegen trauma}

De multidisciplinaire richtlijn voor PTSS-behandeling ${ }^{18}$ schrijft, op basis van het bestaande onderzoek, traumagerichte cognitieve gedragstherapie (CGT) en Eye Movement Desensitization and Reprocessing (EMDR) voor als eerste keus behandeling. De belangrijkste onderdelen van een traumagerichte CGT-behandeling zijn

15 E. van Ee \& R.J. Kleber, 'Child in the shadowlands', The Lancet 2012, p. 642-643; E. van Ee \& J. Blokland, 'Bad Blood or My Blood: A Qualitative Study into the Dimensions of Interventions for Mothers with Children Born of Sexual Violence', International Journal of Environmental Research \& Public Health 2019, p. 4810.

16 Meervoudige partijdigheid is een term uit de systeemtherapie waarbij de hulpverlener bij conflicten in een gezin probeert te voorkomen dat hij door de gezinsleden wordt ingedeeld bij een van de partijen. Dat bekent niet dat de therapeut neutraal is, maar zich weet te verplaatsten in de positie van de verschillende betrokkenen. Zie ook I. Boszormenyi-Nagy \& B.R. Krasner, Tussen geven en nemen. Over contextuele therapie, Haarlem: De Toorts 1986.

17 S.T. Fiske \& S.E. Taylor, Social cognition, from brains to culture, Londen: Sage Publications Ltd. 2017.

18 Trimbos Instituut, Multidisciplinaire richtlijn angststoornissen, Utrecht: Trimbos 2013. 
herhaalde blootstelling aan beelden van de traumatische gebeurtenis en daadwerkelijke blootstelling aan situaties die in het dagelijks leven vermeden worden. ${ }^{19}$ De belangrijkste onderdelen van een EMDR-behandeling zijn eveneens blootstelling aan beelden van de traumatische gebeurtenis, met daarbij afleidende stimuli zoals afwisselende oogbewegingen, handtappen of oortikken om het informatieverwerkingsproces te bevorderen. ${ }^{20}$ De keuze voor een behandeling hangt af van de vaardigheden van de therapeut en de wensen van de cliënt. Indien de behandeling niet effectief blijkt te zijn, is het voorschrift om over te schakelen op de andere eerste keus behandeling. Opvallend is dat met name EMDR veel naamsbekendheid heeft verworven, waardoor cliënten, maar ook bedrijfsartsen en leidinggevenden vragen of EMDR toegepast kan worden. Het is alsof EMDR het wondermiddel is voor elk probleem. Daarbij worden twee dingen uit het oog verloren. Ten eerste, EMDR richt zich voornamelijk op het doorbreken van herbelevingen en vermijding, terwijl aan PTSS en trauma gerelateerde problematiek een veel breder spectrum aan problemen kan omvatten. Wanneer er sprake is van vroegkinderlijke traumatisering of meervoudige traumatisering, zoals bij vluchtelingen of mensen werkzaam in geüniformeerde beroepen (militairen, politie, ambulancepersoneel, brandweer), is vaak het dagelijks functioneren van mensen, soms ernstig, aangedaan. Een traumagerichte behandeling dient dan aangevuld te worden met een behandeling gericht op herstel van het functioneren. ${ }^{21}$ Ten tweede, EMDR is niet voor iedereen (even) effectief. Onderzoek laat zien dat bijvoorbeeld veteranen minder profiteren van een traumagerichte behandelingen zoals EMDR dan andere groepen met PTSS. Hoewel de PTSS-klachten gedurende een richtlijnbehandeling significant afnemen, behoudt een derde tot twee derde van de veteranen hun PTSS-diagnose met aanzienlijke verschillen in restsymptomen. ${ }^{22}$ Maar ook van asielzoekers en vluchtelingen is bekend dat zij minder profiteren van een EMDR-behandeling. ${ }^{23}$ Factoren als type klachten, ernst van de klachten, maar ook de context waarin de traumatische gebeurtenis plaatsvond en waarin de cliënt zich nu bevindt, blijken van invloed op een verminderd behandelresultaat. Om die reden zijn er andere traumagerichte behandelingen ontwikkeld, zoals nar-

19 E.B. Foa, T.M. Keane \& M.J. Friedman, 'Guidelines for treatment of PTSD', Journal of Traumatic Stress 2000, p. 539-588.

20 F. Shapiro, Eye Movement Desensitization and Reprocessing: Basic Principles, Protocols, and Procedures, New York: Guilford Press 2001.

21 E. van Ee e.a., 'Meer herstel voor veteraan én gezin', Tijdschrift voor Gezondheidswetenschappen 2017, p. 80-85. J. Hermans, Trauma en herstel, de gevolgen van geweld - van mishandelingen thuis tot politiek geweld, Amsterdam: Wereldbibliotheek 2016.

22 J. Goodson e.a., 'Treatment of posttraumatic stress disorder in U.S. combat veterans: a metaanalytic review', Psychological Reports 2011, p. 573-599. M. Steenkamp, B. Litz \& C.W. Hoge, 'Psychotherapy for Military-Related PTSD, A Review of Randomized Clinical Trials', JAMA The Journal of the American Medical Association 2015, p. 314.

23 J.F.G. Haagen e.a., 'Predicting post-traumatic stress disorder treatment response in refugees: Multilevel analysis', British journal of clinical psychology 2017, p. 69-83. 
ratieve exposuretherapie voor vluchtelingen ${ }^{24}$ en beknopte eclectische psychotherapie voor PTSS voor politieambtenaren. ${ }^{25}$ Inmiddels worden deze behandelingen ook effectief voor andere doelgroepen ingezet. Daarnaast kan een behandeling aangevuld worden met onder andere technieken gericht op het stabiliseren van emoties, verwerken van rouw, begrijpen van betekenissen en herstel van gezinsrelaties. Een goede traumabehandeling richt zich onzes inziens niet alleen op de behandeling van symptomen, maar op de behandeling van een mens die klachten ervaart en leeft in zijn context. We borduren weer voort op de casus.

Vader start met de narratieve exposuretherapie, de richtlijnbehandeling voor PTSS bij vluchtelingen. In deze behandeling staan de traumatische gebeurtenissen als onderdeel van de levensgeschiedenis van de persoon centraal. Gedurende deze therapie bespreekt vader zijn traumatische ervaringen, waaronder het zien van lijken van verkrachte vrouwen. Hij durft dan voor het eerst te delen dat hij ook heeft gezien hoe mannen verkracht werden en hoe hij heeft gevreesd dat dit ook hem zou overkomen. Als in het dagelijks leven de eer van de familie ter sprake komt, flitsen deze beelden onmiddellijk voor zijn ogen en voelt hij de stress in zijn lijf jagen. In aanloop naar het doorwerken van deze traumatische ervaringen neemt de druk op het gezin toe, daar vader opnieuw zich uitermate beperkend opstelt richting dochter. De woede-uitbarstingen nemen toe. Er wordt een extra gezinsgesprek ingelast om afspraken te maken over hoe geweld te voorkomen. Wanneer de traumatische ervaringen doorgewerkt zijn, nemen de PTSS-symptomen en woede-uitbarstingen verder af en komt het gezin tot rust.

Doordat er verschillende meningen in de geestelijke gezondheidszorg bestaan over de vormgeving van een traumabehandeling, en veel behandelaren slechts geschoold zijn in één methode, veelal EMDR, bepalen de overtuiging en de vaardigheden van de behandelaar welke traumabehandeling aangeboden wordt en welke mogelijkheden er zijn om door te schakelen naar een andere methode. Een goede behandeling is echter altijd gestoeld op drie principes: de evidentie van interventies, klinische expertise én de cliënt als mens in zijn context. ${ }^{26}$ Een dergelijke insteek vereist kennis van en ervaring met meerdere onderbouwde traumagerichte methoden, waardoor wisselen van methode, wanneer nodig, mogelijk is. Daarnaast vereist deze insteek dat de behandelaar verder kijkt dan vermijding en herbeleving en dat de behandeling van aan trauma gerelateerde problematiek

24 N. Gwozdziewycz \& L. Mehl-Madrona, 'Meta-analysis of the use of narrative exposure therapy for the effects of trauma among refugee populations', The Permanente Journal 2013, p. 70-76; J.C.G. Lely e.a., 'Randomised controlled trial comparing narrative exposure therapy with presentcentred therapy for older patients with post-traumatic stress disorder', The British Journal of Psychiatry 2019, p. 369-377.

25 B.P.R. Gersons e.a., 'Randomized Clinical Trial of Brief Eclectic Psychotherapy for Police Officers with Posttraumatic Stress Disorder', Journal of Traumatic Stress 2000, p. 333-347; R.J.L. Lindauer e.a., 'Effects of Brief Eclectic Psychotherapy in Patients with Posttraumatic Stress Disorder: Randomized Clinical Trial', Journal of Traumatic Stress 2005, p. 205-212.

26 J.C. Norcross, Psychotherapy relationships that work: Evidence-based responsiveness, New York: Oxford University Press 2011; B. Wampold \& Z. Imel, The Great Psychotherapy Debate, New York: Lawrence Erlbaum 2015. 
onderdeel is van de behandeling. En ten slotte vereist het begrip van cliënts culturele en sociale context om het dagelijks functioneren van de cliënt daadwerkelijk te kunnen versterken. Alleen dan wordt zorg maatwerk.

\section{Slot}

Met deze bijdrage hebben wij laten zien dat we enerzijds blij zijn met het gegeven dat er meer oog is voor andere dan culturele verklaringen voor de ernstige problemen waar sommige burgers van ons land mee te kampen hebben. Maar net zo goed als een eenzijdige culturele verklaring geen recht doet aan de complexe realiteit, geldt dat ook voor benaderingen op het gebied van trauma: ook daar dient nuance te worden betracht: trauma verklaart ook niet alles en trauma behelst meer dan alleen PTSS. In dit artikel hebben wij om die reden met name aandacht gevraagd voor de verschillende gevolgen van trauma. De meeste mensen reageren veerkrachtig op een traumatische ervaring, sommige ontwikkelen PTSS of aan trauma gerelateerde problematiek. Het begrijpen van deze soms complexe problematiek vraagt een bredere blik dan de diagnose PTSS. De richtlijnbehandeling voor PTSS adviseert EMDR en traumagerichte CGT als effectieve methode. Omdat deze behandeling niet voor iedereen even effectief of voldoende dekkend is, vereist traumazorg specialisatie die niet overal in de ggz geboden wordt. Met andere woorden: maatwerk in de (veiligheids)zorg is zowel menselijk als noodzakelijk. Tot slot kijken we nog een keer terug naar hoe het het gezin in de casus is vergaan.

De behandeling van vader en het gezin wordt beëindigd. Op dit moment is vader klachtenvrij. Maar doordat vader zijn verbondenheid met het land van herkomst en bepaalde culturele overtuigingen koestert, is het mogelijk dat PTSS-symptomen of de dreiging van eergeweld in de toekomst opvlammen. Er is echter voldoende relatie opgebouwd om erop te vertrouwen dat gezinsleden in deze situatie hun weg zullen vinden naar de hulpverlening. 